\title{
ANALISIS PENERAPAN AKUNTANSI AKTIVA TETAP PADA PT PLN (PERSERO) WILAYAH SULSEL, SULTRA DAN SULBAR AREA MAKASSAR SELATAN
}

\author{
Bakri $^{1 *}$, Adriani $^{2}$ \\ ${ }^{1}$ Sekolah Tinggi Ilmu Ekonomi LPI Makassar \\ Email: bakri@stie-lpi.ac.id \\ ${ }^{2}$ Sekolah Tinggi Ilmu Ekonomi LPI Makassar \\ Email: adrianiibrahim@yahoo.com
}

\begin{abstract}
This study aims to assess the extent to which the company has implemented a fixed asset accounting policies are in accordance with the theory, based on Statement of Financial Accounting Standards (SFAS) 16 in 2009 revision in 2007 article 16 said that fixed assets are tangible assets ob tained in the form of ready to use or built in advance that are used in the operation of the company not intended to be sold in the framework of normal business activities and have a useful period of more than one year. The method used a comparative descriptive. The results of the study concluded PT PLN (Persero) Area Makassar Selatan run accounting activities based on the company's accounting policies that have led to SFAS 16. The company shrink its fixed assets using the declining balance method in which it is not in accordance with the applicable accounting standards, the company stopped fixed assets that are not used to how to remove fixed assets from the list and remove it by way of ownership is granted. The company has presented the financial statements in accordance with accounting standards and disclose some information in the notes to the financial statements. Thus, the authors suggested that management has revalued on a regular basis and calculates depreciation using the methods set out in the financial accounting standards, so companies can ensure the carrying amount does not differ at the end of the reporting period.
\end{abstract}

Keywords: Fixed Asset, SFAS no.16

\begin{abstract}
ABSTRAK
Penelitian ini bertujuan untuk menilai sejauh mana perusahaan telah menerapkan kebijakan akuntansi aktiva tetap sesuai dengan teori, berdasarkan Pernyataan Standar Akuntansi Keuangan (PSAK) 16 tahun 2009 revisi tahun 2007 pasal 16 mengatakan bahwa aktiva tetap adalah aktiva berwujud Diperoleh dalam bentuk siap pakai atau dibangun di muka yang digunakan dalam operasi perusahaan yang tidak dimaksudkan untuk dijual dalam rangka kegiatan bisnis normal dan memiliki masa manfaat lebih dari satu tahun. Metode yang digunakan deskriptif komparatif. Hasil penelitian menyimpulkan PT PLN (Persero) Area Makassar Selatan menjalankan kegiatan akuntansi berdasarkan kebijakan akuntansi perusahaan yang telah mengarah pada PSAK 16. Perusahaan menyusutkan aset tetapnya dengan menggunakan metode saldo menurun dimana tidak sesuai dengan standar akuntansi yang berlaku, perusahaan menghentikan aset tetap yang tidak terbiasa dengan cara menghapus aset tetap dari daftar dan menghapusnya dengan cara kepemilikan diberikan. Perusahaan telah menyajikan laporan keuangan sesuai dengan standar akuntansi dan mengungkapkan beberapa informasi dalam catatan atas laporan keuangan. Dengan demikian, penulis menyarankan bahwa manajemen telah melakukan revaluasi secara teratur dan menghitung penyusutan dengan menggunakan metode yang ditetapkan dalam standar akuntansi keuangan, sehingga perusahaan dapat memastikan jumlah tercatat tidak berbeda pada akhir periode pelaporan.
\end{abstract}

Kata kunci: Aset Tetap, SFAS no.16 


\section{PENDAHULAN}

Aktiva tetap mempunyai peranan yang penting dalam usaha. Untuk mendukung suatu usaha dalam kemajuan perusahaan dibutuhkan peralatan ataupun perlengkapan yang merupakan salah satu bagian dari aktiva tetap. Peranan aktiva tetap sangat besar yang merupakan investasi persahaan. Dimana aktiva tetap merupakan aset atau investasi yang bernilai besar dalam kelangsungan hidup perusahaan.

Aktiva tetap yang digunakan dalam laporan keuangan mempunyai masa atau periode akuntansi yang berguna dalam rekap pembuatan laporan keuangan. Dalam memanfaatkan aktiva tetap perusahan harus mempergunakan aktiva tetap secara baik dalam proporsi yang signifikan terhadap jumlah aset yang dimiliki dalam perusahaan. Aktiva tetap mempunyai batas tertentu dalam penggunaan untuk kepentingan perusahaan, dimana aktiva tetap bisa juga tidak difungsikan kembali untuk kemajuan perusahaan, sehingga aktiva tetap dapat dihentikan. Penghentikan aktiva tetap dapat dilakukan dengan menjual kembali atau ditukarkan kembali yang dapat dijadikan aset kembali untuk kepentingan perusahaan.

Aset tetap atau investasi dapat dihentikan dalam pengakuan aset tetap yaitu: (a) pada saat pelepasan atau dibuang; atau (b) pada saat tidak dapat digunakan untuk aset tetap atau tidak dapat digunakan kembali sesuai (PSAK No 16). Aktiva tetap dalam perusaahan yang diteliti pada PT PLN Sulsel, Sultra Dan Sulbar Area Makassar Selatan merupakan aset atau investasi besar dalam kemajuan perusahaan

Aktiva tetap pada PT. PLN (Persero) Wilayah Sulsel, Sultra Dan Sulbar Area Makassar Selatan merupakan investasi yang penting dalam kepentingan perusahaannya. Untuk kemajuan kegiatan dalam perusahaan sangat dibutuhkan akrtiva tetap contohnya gedung, bangunan, kendaraan, mesin, perlengkapan, peralatan, penyaluran tenaga listrik, jaringan distribusi, gardu distribusi, perlengkapan transmisi data, perlengkapan pengolah data, perlengkapan telekomunikasi, saluran gardu induk, saluran tegangan tinggi, material cadangan, alat mobil dan investasi cadangan lainnya perusahaan dibutuhkan aktiva tetap seperti tanah, bangunan dan kelengkapan halaman, bangunan saluran air, instalasi dan mesin, reaktor nuklir, perlengkapan penyaluran tenaga listrik, gardu induk, saluran udara tegangan tinggi, kabel bawah tanah, jaringan distribusi, gardu distribusi, perlengkapan lain-lain distribusi, perlengkapan pengolah data, perlengkapan transmisi data, perlengkapan telekomunikasi, perlengkapan umum, kendaraan bermotor dan alat yang mobil, dan material cadangan, yang harganya relatif tinggi serta memiliki peranan yang sangat penting pada PT. PLN (Persero) Wilayah Sulsel, Sultra Dan Sulbar Area Makassar Selatan untuk memberikan pelayanan kepada masyarakat melalui penyelenggaraan di bidang produksi transmisi dan distribusi tenaga listrik, sehingga diperlukan adanya penerapan akuntansi aktiva tetap yang tepat.

PT PLN (Persero) Wilayah Sulsel, Sultra Dan Sulbar Area Makassar Selatan merupakan salah satu Badan Usaha Milik Negara (BUMN), didirikan dengan tujuan utama turut serta dalam melaksanakan pembangunan nasional dan meningkatkan kesejahteraan serta memenuhikebutuhan tenaga listrik masyarakat umum. Selain itu juga mempunyai tujuan untuk memperoleh laba, sehingga kegiatan perusahaan dapat terus berjalan dan tetap eksis dalam kondisi yang cepat berubah seperti sekarang ini.

\section{KAJIAN LITERATUR Pengertian Akuntansi}

Akuntansi adalah proses mengidentifikasi, mengukur, mengklasifikasi dan mengikthisar sebuah transaksi ekonomi atau kejadian yang dapat menghasilkan data yang bersifat keuangan yang dapat 
digunakan dalam pengambilan keputusan. American Accounting Asscociation (AAA) menyatakan bahwa akuntansi adalah: "Proses mengidentifikasikan, mengukur, dan melaporkan informasi ekonomi, untuk memungkinkan adanya penilaian dan keputusan yang jelas dan tegas bagi mereka yang menggunakan informasi tersebut". Harahap (2012 : 4) menyatakan bahwa: Akuntansi adalah tool of management. Alat kapitalis untuk mengumpulkan harta dan memeliharanya agar proses akumulasi kekayaan berjalan lancar dan penguasaannya tetap ditangan kapitalis".

\section{Pengertian Aktiva}

Menurut Moelyati (2004:9) aktiva (assets) adalah semua hak yang dapat digunakan dalam operasi perusahaan. Menurut Sumardi (2004:12) aktiva menunjukkan segala bentuk kekayaan yang dimiliki oleh perusahaan dan merupakan sumber daya bagi perusahaan dalam menjalankan aktivitas bisnisnya.

Menurut Suyoto (2005:25) aktiva terbagi menjadi dua kelompok, yaitu: Aktiva lancar (current assets) adalah kas dan aktiva lainnya yang diharapkan akan dapat dikonversi menjadi kas, dijual, atau dikonsumsi dalam satu tahun atau dalam satu siklus operasi, tergantung mana yang paling lama. Perusahaan biasanya mempunyai bermacam-macam bentuk aktiva lancar didalam kegiatan operasionalnya seperti: kas, deposito bank, surat berharga, piutang usaha, piutang wesel, persediaan barang dagangan, perlengkapan kantor, perlengkapan toko, beban dibayar dimuka, pendapatan yang masih harus diterima.

Aktiva tetap adalah Aktiva tetap (fixed assets) adalah kekayaan yang bersifat tahan lama yang digunakan dalam operasi reguler perusahaan. Perusahaan biasanya mempunyai bermacam-macam bentuk aktiva tetap didalam kegiatan operasionalnya seperti: tanah, mesin-mesin, peralatan, kendaraan, bangunan. Aktiva berwujud yang diperoleh dalam bentuk siap pakai atau dengan dibangun lebih dahulu, yang digunakan dalam operasi perusahaan, tidak dimaksud untuk yang ada dalam perusahaan yang mempunyai nilai jual relatif tinggi pada PT. PLN (Persero) Wilayah Sulsel, Sultra dan Sulbar.

Dibidang produksi transmisi dan distribusi tenaga listrik digunakan pada PT PLN (persero) wilayah sehingga adanya penerapan akuntansi aktiva tetap yang sesuai yang dilakukan PT PLN (Persero) Wilayah Sulsel, Sultra dan Sulbar. PT. PLN Wilayah Sulsel, Sultra dan Sulbar. PT. PLN (Persero) wilayah Sulsel, Sultra dan Sulbar Area Makassar Selatan merupakan salah satu Badan Usaha Usaha Milik Negara yang mempunyai milik pemerintah. Selain itu perusahaan mempunyai tujuan yaitu memperoleh laba atau keuntungan yang besar. Tujuan perusahaan dalam memperoleh laba atau keuntungan yang besar dapat menjadikan suatu perusahaan yang mempunyai kegiatanyang dapat berjalan dan tetap eksis sehingga kondisi perusahaan berjalan sebagaimana yang diharapkan.

\section{Pengukuran Aktiva Tetap}

Pengukuran aktiva tetap terjadi ketika pengakuan awal dan setelah aktiva tetap telah diakui. Pengukuran aktiva pada saat pengakuan awal dilakukan dengan mengukur semua biaya perolehan. Dan ketika aktiva telah diakui perusahaan, mengukur aktiva menggunakan dua metode yaitu metode biaya dan metode revaluasi.

\section{Penyusutan dan Metode Penyusutan Aktiva Tetap.}

Metode penyusutan adalah suatu cara yang sistematis dan rasional tentang bagaimaharga perolehan aktiva dialokasikan sebagai biaya operasional sepanjang umur aktiva tetap tersebut. Untuk pengalokasian dan menghitung beban penyusutan ada bermacam-macam metode penyusutan yang dapat digunakan. Hal ini tergantung pada kebijaksanaan dan pertimbangan yang diambil oleh masingmasing perusahaan. Berdasarkan Ikatan Akuntan Indonesia PSAK Nomor 16 
Paragraf 11 (2011:16 paragraf 11) mengungkapkan bahwa metode-metode penyusutan dapat dilakukan dengan berbagai metode yang dapat dikelompokkan menurut metode garis lurus, Metode saldo menurun dan metode jumlah unit. Penyusutan adalah pengalokasian harga perolehan aktiva tetap menjadi beban kedalam periode akuntansi. Dan untuk mengukur beban penyusutan harus menggunakan metode penyusutan yang sesuai serta diterapkan secara konsisten.

\section{Hipotesis Penelitian}

Hipotesis merupakan jawaban sementara terhadap masalah yang bersifat praduga karena masih harus diuji kebenarannya. Berdasarkan kajian teoritis, penelitian yang relevan dan kerangka berpikir diatas dapat ditarik hipotesis penelitian: "Diduga Penerapan Akuntansi Aktiva Tetap pada PT. PLN (Persero) Wilayah Sulsel, Sultra dan Sulbar Area Makassar Selatan belum sesuai dengan PSAK Nomor 16.

\section{METODE PENELITIAN}

Analisis data yang dilakukan dengan menggunakan metode deskriptif dan kuantitatif, dimana penelitian dilakukan cara menyajikan data laporan keuangan periode akuntansi untuk 3 tahun dari tahun 2016 sampai dengan tahun 2018 serta menganalisis data laporan keuangan perusahaan tersebut.

\section{HASIL DAN PEMBAHASAN}

\section{Penerapan Akuntansi Aktiva Tetap}

Berdasarkan PSAK No.16 bahwa aktiva tetap yang telah disajikan dalam neraca sebesar nilai perolehan aktiva tersebut perolehan aktiva tetap dikurangi dalam akumulasi penyusutan. Dalam data laporan keuangan yang disusun secra terperinci dalam bentuk nrerca dan laporan laba rugi, untuk periode akuntansi tahun 2016 sampai dengan tahun 2018, dalam laporan neraca pada
PT PLN Sulsel, Sultra dan Sulbar.

Data laporan neraca tersebut terdapat aktiva tetap perusahaan contohnya tanah, bangunan, atau hak investasi lainnya dalam perusahaan. Dalam hal ini perusahaan ini sudah menerapkan kebijakan yang tersuisun dengan baik sehingga kebijakan yang diberikan perusahaan dapat berjalan sebagaimana mestyinya. Perusahaan sudah menerapakan kebijakan sehingga kebijakan tidak menyimpang dari hal tidak diinginkan. Dasar pengukuran yang digunakan dalam perusahaan untuk menentukan jumlah tercatat bruto atau laba. Dapat diuraikan dan tabel yang digunakan

\begin{tabular}{|c|c|c|c|}
\hline KETfiRANGAN & $\begin{array}{l}\text { ER 3 I } \\
\text { ESEMBER } \\
2016\end{array}$ & $\begin{array}{c}\text { PER 31 } \\
\text { DECEMBER } \\
2017\end{array}$ & $\begin{array}{l}\text { PER 31 } \\
\text { DESEMBER } \\
2018\end{array}$ \\
\hline \multicolumn{4}{|l|}{ Aset } \\
\hline \begin{tabular}{|l} 
TWIAP \\
INETTO)
\end{tabular} & 80 & $\{0$ & 2 \\
\hline $\begin{array}{l}\text { feet Temp } \\
\text { Bruto }\end{array}$ & $\begin{array}{r}1312,544,187 \\
, 812\end{array}$ & $\begin{array}{r}1, \mathrm{~B} 36,784,867 \\
, 518\end{array}$ & $\begin{array}{r}1,327, \mathrm{U} 68, \mathrm{U} 35 \\
\text { fi57 }\end{array}$ \\
\hline Penyusutan & $\begin{array}{r}631,124,839 \\
6491 \\
\end{array}$ & $\begin{array}{r}\langle 4+\mathrm{J}, 699,141,2 \\
08)\end{array}$ & $<71,691441, \mathrm{U}$ \\
\hline \begin{tabular}{|l} 
Perkerjaan \\
dalam \\
pelaksanaan
\end{tabular} & $\begin{array}{r}12, \mathrm{~B} 45,75 \mathrm{~S}, \mathrm{~B} 3 \\
4\end{array}$ & 2,B I9,B57, 864 & $3,499, \mathrm{~S} 42,3 \mathrm{R}$ \\
\hline \multicolumn{4}{|l|}{$\begin{array}{l}\text { PROPHRTI I } \\
\text { INVESTAS I }\end{array}$} \\
\hline \multicolumn{4}{|c|}{ Investasi Jangka panjang } \\
\hline SECTION & 9 (i 3,1 22,221 & $1,21 \mathrm{U}, 222,039$ & $1,32 \mathrm{i}, 313,\left(\mathrm{i} 1^{\wedge}\right.$ \\
\hline $\begin{array}{l}\text { Aset Tidak } \\
\text { Beroperasi }\end{array}$ & & & \\
\hline $\begin{array}{l}\text { Lain (Jk. } \\
\text { Panjang) }\end{array}$ & & & \\
\hline $\begin{array}{l}\text {-Pihak Yang } \\
\text { Berelosi }\end{array}$ & $903,122,221$ & $1,21 \mid \mathrm{J}, 222,139$ & $1,327,313, \mathrm{U1}{ }^{*}$ \\
\hline $\begin{array}{l}\text { Biay a Yang } \\
\text { Ditong guhka }\end{array}$ & & & \\
\hline
\end{tabular}

\section{Penyajian Aktiva Tetap Laporan Laba Rugi}

Sebagaimana diketahui bahwa setiap perubahan tentunya membutuhkan aktiva tetap untuk menunjang kegiatan perubahan. Tanpa adanya aktiva tetap yang berupa peralatan, perlengkapan dan aset lainnya maka perusahaan tidak akan dapat menjalankan kegiatan dengan baik. sehingga aktiva tetap merupakan aktiva tetap berwujud yang perusahaan digunakan dalam waktu jangka panjang. 
Aktiva tetap sebagai salah satu komponen dari dalam laporan keuangan (neraca) harus disajikan secara tepat agar bermanfaat bagi para pemakai laporan keuangan. Kewajaran penyajian aktiva tetap dineraca dipengaruhi oleh beberapa faktor diantaranya adalah kebijaksanaan akuntansi aktiva tetap dari penyusutan. Benar kecilnya biaya penyusutan secara periodik dipengaruhi oleh penentuan harga perolehan aktiva tetap nilai residu pada akhir masa penggunaannya, umur ekonomis atau masa kegunaan.

\begin{tabular}{|c|c|c|c|}
\hline \begin{tabular}{|l|l|} 
V & Uraian \\
L & \\
\end{tabular} & $\begin{array}{c}\text { Per31 } \\
\text { Oeseinber } 2016\end{array}$ & $\begin{array}{c}\text { Per 31 } \\
\text { Desember } \\
2017\end{array}$ & $\begin{array}{c}\text { Per 31 } \\
\text { Desember } \\
2018\end{array}$ \\
\hline \multicolumn{4}{|l|}{ A SET } \\
\hline $\begin{array}{l}\text { Aset Tetap } \\
\text { (Bruto) }\end{array}$ & & & \\
\hline $\begin{array}{l}\text { Pembangkita } \\
\text { n }\end{array}$ & & & \\
\hline $\begin{array}{l}\text { 1. Pembangkit } \\
\text { PLTA }\end{array}$ & & & \\
\hline \begin{tabular}{l|l} 
2. & Pembangkit \\
PLTU
\end{tabular} & & & \\
\hline $\begin{array}{l}\text { 3. Pembangkit } \\
\text { PLTD }\end{array}$ & $5,127,59,17.1$ & $5,297 \mathrm{~J} 47.057$ & $\mathrm{t}, \mathrm{tl} 199, \mathrm{ltJ} 9, \mathrm{tJ} t \mathrm{l} 2$ \\
\hline $\begin{array}{l}\text { 4. } \begin{array}{l}\text { Pembangkit } \\
\text { PLTG }\end{array} \\
\end{array}$ & & & \\
\hline $\begin{array}{l}\text { 5. Pembangkit } \\
\text { PLTP }\end{array}$ & & & \\
\hline $\begin{array}{l}\text { 6. } \begin{array}{l}\text { Pembangkit } \\
\text { PLTGU }\end{array} \\
\end{array}$ & & & \\
\hline 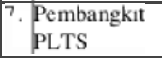 & & & \\
\hline Jumlah & $4,749,785,26$ & $2 \$ 142,33 \mathrm{t}$ & $22,42 \mathrm{t} 1,937,72$ \\
\hline Transmıs1 & & & \\
\hline
\end{tabular}

\section{Penyajian Aktiva Tetap Laporan Laba Rugi}

Aktiva tetap yang tercantum pada model biaya yang merupakan kebijakan perusahaan yang terdapat dalam perolehan aset terhadap aktiva tetap. Pada model biaya setelah diakui sebagai aktiva, aktiva tetap dicatat sebesar biaya perolehan dikurangi akumulasi penyusutan dan akumulasi rugi penurunan aktiva, yang terdapat dalam PSAK no 16.. Dari hasil penelitian, pihak perusahaan akan melakukan pencatatan dalam laporan keuangan untuk tahun 2016 sampoai tahun 2018. Dalam hal ini pihak perusahaan harus menerapkan pencatatan yang jelas sampai pada pencatatan biaya perolehannya dikurangi akumulasi penyusutan dan akumulasi rugi penurunan aktiva yang mana harus sesuai dengan kebijakan-kebijakan yang ada pada PSAK 16.

\section{Penyajian Aktiva Tetap Laporan Laba Rugi}

Sebagaimana diketahui bahwa setiap perubahan tentunya membutuhkan aktiva tetap untuk menunjang kegiatan perubahan. Tanpa adanya aktiva tetap yang berupa peralatan perlengkapan dan aset lainnya maka perusahaan tidak akan dapat menjalankan kegiatan dengan baik, sehingga aktiva tetap merupakan aktiva tetap berwujud yang perusahaan digunakan dalam waktu jangka panjang. Aktiva tetap sebagai salah satu komponen dari dalam laporan keuangan (neraca) harus disajikan secara tepat agar bermanfaat bagi para pemakai laporan keuangan. Kewajaran penyajian aktiva tetap dineraca dipengaruhi oleh beberapa faktor diantaranya adalah kebijaksanaan akuntansi aktiva tetap dari penyusutan. Benar kecilnya biaya penyu sutan secara periodic dipengaruhi oleh penentuan harga perolehan aktiva tetap nilai residu pada akhir masa penggunaannya, umur ekonomis atau masa kegunaan.

\section{KESIMPULAN DAN SARAN}

\section{Kesimpulan}

Berdasarkan hasil pembahasan maka PT PLN (Persero) Area Makassar Selatan dalam hal melaksanakan kegiatan akuntansinya berpedoman pada Kebijakan Akuntansi PT PLN (Persero) Area Makassar Selatan yang pada prinsipnya sudah mendekati Pernyataan Standar Akuntansi Keuangan (PSAK) No.16 yaitu 1. PT PLN (Persero) Area Makassar Selatan 
hanya melakukan pencatatan yang didasarkan atas harga perolehannya saja, pihak perusahaan tidak menerapkan pencatatan yang lebih jelas sampai pada pencatatan biaya perolehannya dikurangi akumulasi penyusutan dan akumulasi rugi penurunan aktiva yang mana harus sesuai dengan kebijakan-kebijakan yang berpedoman pada PSAK No.16.

2. PT PLN (Persero) Area Makassar Selatan pada penyusutan aktiva tetap hanya dilakukan dengan menggunakan metode saldo menurun (declining balance method). Sementara Menurut PSAK No. 16 penyusutan yang digunakan untuk mengalokasikan jumlah yang disusutkan sistematis dari suatu aktiva selama umur manfaatnya antara lain, metode garis lurus, metode saldo menurun, metode jumlah unit.

\section{Saran}

Saran yang dapat diberikan penulis sebagai berikut :

1. Diharapkan Revaluasi secara teratur, agar perusahaan bisa memastikan bahwa jumlah tercatat tidak berbeda secara material dari jumlah yang ditentukan dengan menggunakan nilai wajar pada periode pelaporan.

2. Diharapkan dalam menghitung penyusutan, perusahaan menggunakan metode-metode yang diatur dalam Standar Akuntansi Keuangan, agar perlakuan aktiva bisa dilakukan sesuai dengan jenis-jenis aktiva tetap.

\section{DAFTAR PUSTAKA}

Harahap, S.S. 2011. Teori Akuntansi Edisi Revisi 2011. Penerbit PT Raja Grafindo Persada. Jakarta.

Harahap, Sofyan Syafiri. 2012. Teori Akuntansi. Edisi Revisi-Cet 12. Penerbit Rajawali Pers. Jakarta. ke-6, Jilid 1. PT Indeks, Jakarta.

Ikatan Akuntansi Indonesia. 2011. Standar Akuntansi Keuangan. Jakarta: Penerbit Salemba Empat.

Ikatan Akuntansi Indonesia. 2011. PSAK 16 (Revisi 2009):Aset Tetap.IAI, Jakarta.
Ikatan Akuntansi Indonesia. 2011. PSAK 16 (Revisi 2011):Aset Tetap.IAI, Jakarta.

Ikatan Akuntansi Indonesia.2014. Standar Akuntansi Keuangan Per Efektif 1 Januari 2015. Penerbit Ikatan Akuntansi Indonesia.

Ikatan Akuntan Indonesia. 2015. Pernyataan Standar Akuntansi Keuangan.

Juan, Ng Eng dan Wahyuni, Ersa Tri2012. Panduan Praktis Standar Akuntansi Keuangan Berbasis IFRS Edisi 2. Jakarta: Penerbit Salemba Empat.

Lubis, Arfan Ikhsan.2010. Akuntansi Keperilakuan, Edisi 2. Salemba Empat, Jakarta. 